\title{
A centralidade da experiência na constituição das representações: contribuições interdisciplinares para o campo da comunicação
}

Paula Guimarães Simões

\section{Resumo}

0 objetivo deste artigo é discutir o papel da experiência na constituição das representações. Para tanto, define a noção de experiência, analisando a abordagem pragmatista de John Dewey e algumas contribuições contemporâneas. Discute, em seguida, o conceito de representação, explorando a concepção clássica de Durkheim, a ideia de mimese de Paul Ricoeur e a noção de imaginação simbólica de Gilbert Durand. 0 artigo destaca a complexidade e a dinamicidade que marcam os fluxos de significação. Ele enfatiza o papel do simbólico na construção dos sujeitos e da sociedade, bem como a dimensão interativa da experiência. Ressalta, ainda, a mútua construção entre experiência e representação, algo central para as análises no campo da comunicação.

\section{Palavras-chave}

Representação. Experiência.

Comunicação. Interação.

Paula Guimarães Simões |

paulaguimaraessimoes@yahoo.com.br

Doutoranda em Comunicação Social pela Universidade Federal de Minas Gerais - UFMG. Pesquisadora do Grupo de Pesquisa em Imagem e Sociabilidade - GRIS - e Bolsista da Coordenação de Aperfeiçoamento de Pessoal de Nível Superior - CAPES.

\section{Introdução}

As representações povoam a vida cotidiana. Se as tomamos, inicialmente, como redes de significados que permeiam um contexto, podemos pensar nas inúmeras representações que irrigam nossa vida prática: provenientes da família, do mundo do trabalho, dos valores sociais, das profissões, das cidades, da mídia. Essas redes simbólicas são construídas pelos indivíduos na configuração do mundo intersubjetivo. Para tentar compreender esse universo simbólico, as várias ciências sociais se debruçaram sobre 0 terreno das representações de diferentes formas. No campo da comunicação, a análise desse fenômeno também ocupa um lugar central e aciona contribuições de outras disciplinas para a sua compreensão.

Adotando uma perspectiva que aborda a comunicação como um processo de interação, entendemos que as representações devem ser pensadas a partir de um olhar relacional. Olhar esse que busca dar conta das interações que colocam em jogo indivíduos, significados e 
contextos na configuração das representações.

Ressaltamos, contudo, que, devido à

complexidade do conceito e do fenômeno das representações, "não é possível encontrar uma 'tradução' clara do seu significado e da sua força, a configuração de um sentido, mas antes um mapa de possibilidades" (FRANÇA, 2004, p. 18, grifo da autora).

0 objetivo deste artigo é traçar um desses mapas de possibilidades para refletir sobre as representações, procurando evidenciar a centralidade da experiência na constituição das mesmas. Para tanto, discute-se, inicialmente, 0 conceito de experiência, a partir da perspectiva pragmatista de John Dewey e de contribuições de outros pesquisadores mais contemporâneos. Em seguida, o texto busca retomar algumas concepções de representação que incitam a reflexão sobre a relação entre esta e a experiência. Partimos da clássica conceituação de Durkheim e acionamos, na sequência, algumas contribuições de dois autores franceses cuja discussão, realizada na década de 1980, ajuda a refletir sobre essa relação entre experiência e representação: Paul Ricoeur e Gilbert Durand.

As abordagens desses dois autores permitem enfatizar o papel do simbólico na construção dos sujeitos e da vida social, bem como a natureza interativa que constitui a experiência. Assim, tais perspectivas trazem contribuições para rearticular experiência e representação nas análises que são realizadas no campo da comunicação.

\section{A noção de experiência}

A experiência se refere ao nosso estar no mundo, ao modo como o apreendemos, como nos relacionamos com ele e com os outros indivíduos na vida cotidiana. Essa dimensão interacional e prática ${ }^{1}$ da experiência é enfatizada por John Dewey. Segundo o pragmatista, "toda experiência é o resultado de interação entre uma criatura viva e algum aspecto do mundo no qual ela vive" (DEWEY, 1980, p. 95). Para o autor, a experiência acontece continuamente, pois a interação entre o ser vivo e as condições que o cercam "está implicada no próprio processo da vida" (DEWEY, 1980, p. 89). Como analisam Guimarães e Leal, "sendo 'interação', a experiência para Dewey está implicada nas condições e nas dimensões concretas da relação do indivíduo com 0 ambiente e, consequentemente, não pode ser caracterizada por outro aspecto exclusivamente" (GUIMARÃES; LEAL, 2008, p. 5-6).

A experiência deve, assim, ser pensada a partir do contexto concreto dos indivíduos e envolve as ações racionais e emocionais que eles realizam no mundo. Ela se desenvolve como um processo de percepção e interpretação das coisas, que se efetiva a partir de um repertório existente, o qual é atualizado, configurando um processo interativo 
entre os indivíduos, as coisas do mundo e as temporalidades que marcam um contexto.

Além de destacar a interação como elemento central na configuração das experiências, Dewey salienta as diferenças de completude e de intensidade que as caracterizam. Conforme o filósofo, algumas experiências são marcadas por dispersão, fragmentação e monotonia; são incompletas e, por isso, não podem ser pensadas como uma experiência (DEWEY, 1980, p. 89). Aqui, a interação configuradora da experiência é vista como "rotineira, mera repetição, submissa a convenções práticas e procedimentos intelectuais" (GUIMARÃES; LEAL, 2008, p. 6). Em um segundo sentido, a experiência é vista como uma experiência, marcada por completude e intensidade; a interação "pode integrar as várias capacidades humanas, pode mobilizá-las livremente de modo que seu resultado seja uma experiência integral, forte, de rara intensidade" (GUIMARÃES; LEAL, 2008, p. 6).

Em ambos os sentidos, a experiência é entendida como constituída por um duplo movimento: 0 agir e 0 sofrer. 0 sujeito age no mundo, ao mesmo tempo em que sofre alguma coisa em função dessa ação, o que impulsionará 0 agir subsequente. Dewey destaca que, nesse processo, emerge uma "adaptação mútua do eu e do objeto" (DEWEY, 1980, p. 96), evidenciando o papel transformador do sujeito e do mundo através da vivência de uma experiência. É importante destacar, ainda, a associação que o pensador realiza entre experiência e contexto. Se a "experiência é o nome do mais abrangente dos contextos" (DEWEY, 1998, p. 215 apud POGREBINSCHI, 2005, p. 60), é fundamental ressaltar que estes se efetivam a partir da relação entre indivíduo e sociedade.

Em sua discussão sobre as mudanças no modo de abordar as representações que marcaram o desenvolvimento das ciências humanas, Foucault evidencia essa relação entre as experiências individual e coletiva na construção dos sentidos. Segundo o autor,

[...] a cadeia significante por meio da qual se constitui a experiência única do indivíduo é perpendicular ao sistema formal a partir do qual se constituem as significações de uma cultura: a cada instante a estrutura própria da experiência individual encontra nos sistemas da sociedade um certo número de opções possíveis (e de possibilidades escolhidas); inversamente, as estruturas sociais encontram em cada um dos seus pontos de escolha um certo número de indivíduos possíveis (e outros que não 0 são), da mesma maneira que na linguagem a estrutura linear torna sempre possivel num dado momento a escolha entre várias palavras ou vários fonemas (mas exclui todos os outros) (FOUCAULT, 1966, p. 494).

Foucault enfatiza, assim, o papel da linguagem, o qual é central na efetivação da experiência. É a linguagem que marca o ser do homem em sociedade. Como também destaca Rodrigues, "é na e pela linguagem que a experiência se constitui, se revela ou se desvenda o sentido que a enforma" (RODRIGUES, 1991, p. 32). A 
linguagem tem, portanto, um papel constituidor da experiência humana.

Adriano Rodrigues (1991) destaca três funções da linguagem na constituição da experiência:

a) a inspeção, que se refere ao processo em que 0 sujeito acessa 0 mundo; b) a decifragem diz respeito ao processo de interpretação que caracteriza a leitura que o sujeito faz do mundo; c) e a elaboração mítico-poiética que se realiza através da criação de sentidos novos sobre 0 mundo. Nesse processo, segundo o autor, o homem converte sua relação com o meio ambiente em um mundo próprio (1991, p. 27). Para Rodrigues,

A experiência da vida insere-se na relação do homem com o mundo, consigo próprio e com os outros. É nas manifestações simbólicas da cultura que 0 homem preenche 0 abismo que o separa das coisas, de si próprio e dos outros, acedendo assim à consciência reflexiva e à experiência da vida em comum. Pela linguagem, experiência simbólica por excelência, 0 homem prossegue 0 ilimitado trabalho de preenchimento deste abismo e a elaboração de um sentido para o enigma da vida (RODRIGUES, 1991, p. 27).

0 pesquisador destaca, assim, o papel do sujeito ao utilizar a linguagem para preencher de sentidos esse abismo que o separa do mundo. Ao mesmo tempo, Rodrigues destaca a sujeição do indivíduo ao estoque de significados compartilhados presente no mundo intersubjetivo, a partir do qual ele constitui as experiências. Estas se configuram, assim, a partir do quadro cultural de uma sociedade - 0 que também é destacado por Valverde: "atribuímos sentido ao mundo no caldo da cultura, no fluxo das significações, a partir das quais a nossa experiência é sempre retomada. 0 conceito mesmo de experiência nos remete a essa dinâmica de retomada do passado e projeção para o futuro, que caracteriza a existência" (VALVERDE, 2007, p. 256).

Além de evidenciar a natureza simbólica da experiência, Valverde destaca a dimensão temporal que a constitui: uma experiência se efetiva retomando significados instituídos, ao mesmo tempo em que projeta desdobramentos no fluxo que articula essas diferentes temporalidades. A experiência não apresenta, assim, um caráter inaugural em cada contexto, mas ela se insere em um fluxo que a antecede e, a partir dela, novos elementos simbólicos poderão se instituir.

A partir dos autores aqui retomados, pode-se considerar a experiência como resultado da interação entre os homens e 0 mundo, em um processo marcado por ação, padecimento e transformação. Nesse processo, o papel da linguagem é central, já que é ela que institui o fluxo de significações que constrói a experiência em um contexto. Esta se efetiva, assim, na prática dos homens, que articulam sentidos e temporalidades na conformação de sua vivência no mundo. Se entendemos a experiência desta forma, acreditamos que ela é central na constituição de representações, como será discutido na próxima seção. 


\section{Para pensar as representações: o papel da experiência}

As representações podem ser entendidas como universos simbólicos que emergem a partir da experiência dos homens no mundo, sendo que elas "são construídas e ganham sentido em contextos relacionais específicos" (FRANÇA, 2004, p. 25). É a experiência humana que funda as representações, ao mesmo tempo em que estas podem proporcionar novas experiências aos indivíduos, em um processo de configuração mútua. Ou seja,

As representações estão intimamente ligadas a seus contextos históricos e sociais por um movimento de reflexividade - elas são produzidas no bojo de processos sociais, espelhando diferenças e movimentos da sociedade; por outro lado, enquanto sentidos construídos e cristalizados, elas dinamizam e condicionam determinadas práticas sociais. (FRANÇA, 2004, p. 19).

Assim, procuramos discutir essa articulação entre representações e práticas sociais, entre universos simbólicos e experiência. Partiremos da visão clássica de representação em Durkheim e enfatizaremos as perspectivas de dois pensadores mais contemporâneos que complexificam a concepção durkheimiana e trazem ricas contribuições para as análises de representações no campo da comunicação.

\subsection{Retomando um clássico: Durkheim e as representações}

Émile Durkheim é considerado um pioneiro na reflexão sobre as representações no campo das Ciências Sociais. Motivado pela busca de afirmar a Sociologia como ciência, diferenciando-a da Psicologia, o pensador procura distinguir representações individuais e coletivas, destacando a especificidade do objeto sociológico. Para Durkheim (2007), tanto a vida mental do indivíduo como a vida coletiva são feitas de representações. Partindo do indivíduo, as representações agem sobre 0 corpo e 0 espírito, supondo certos movimentos que constituem o curso contínuo de representações da vida psíquica. Conforme 0 autor, "toda representação, no momento onde ela se produz, afeta, além dos órgãos, o próprio espírito, ou seja, as representações presentes e passadas que o constituem" (DURKHEIM, 2007, p. 26). Ele destaca, entretanto, o papel do social na constituição tanto dos indivíduos como das representações. Para Durkheim, "a sociedade é a única fonte da humanidade do homem: é através dela que se transcende a pura vida orgânica que é a condição do homem tomado em sua individualidade" (PEREIRA FILHO, 2004, p. 142).

Dessa forma, as representações que partem da individualidade do homem ganham uma nova existência na vida social; destacando-se do corpo do indivíduo, as representações têm uma existência independente em relação ao seu substrato. Nessa passagem do individual ao coletivo, elas são vistas como dotadas de relativa autonomia, compondo um agregado simbólico superior. "Se se pode dizer, em certos traços, que as representações coletivas são exteriores às 
consciências individuais, é que elas não derivam dos indivíduos tomados isoladamente, mas de seu concurso" (DURKHEIM, 2007, p. 34).

Portanto, é das relações que os indivíduos estabelecem que decorrem as representações coletivas. 0 autor salienta, assim, a relação entre indivíduo e sociedade, entre representações individuais e coletivas. Para Durkheim, a vida representativa só existe a partir da reunião de indivíduos. 0 conjunto de representações que configura a vida social é visto como uma forma estável de compreensão coletiva que atua na integração da sociedade (FRANÇA, 2004, p. 14).

A partir desse viés, percebe-se a centralidade do social na efetivação das representações. Entretanto, 0 autor não desconsidera o papel dos indivíduos no processo. Ainda que ele destaque a constituição de um agregado simbólico superior com vida própria, a construção deste não seria possível sem a atuação dos indivíduos. Dessa forma, podemos considerar que as experiências coletiva e individual (mesmo que esta em menor grau, na abordagem durkheimiana) atuam nesse processo de constituição da vida representativa. ${ }^{2}$ É preciso destacar, ainda, que 0 autor evidencia o papel do simbólico como "instituinte da realidade social" (PEREIRA FILHO, 2004, p. 154). Mas ele não atenta para o processo instituidor das representações através da linguagem; os significados que orientam a vida coletiva existem de modo relativamente independente de suas condições instauradoras. Nesse sentido, ainda que o ponto de partida para a construção das representações seja a vivência dos homens, Durkheim não enfatiza a dimensão da experiência como motor desse processo. As interações entre os homens e 0 mundo que, como discutimos, resultam na experiência humana não são apreendidas pelo sociólogo em todo o seu movimento dinâmico e complexo que edifica as representações. A dinamicidade, a complexidade e o movimento que caracterizam o universo de representações, bem como a sua estreita articulação com a experiência que se realiza através da linguagem, serão percebidas nas discussões de outros autores, como Paul Ricoeur e Gilbert Durand, conforme será analisado a seguir.

\subsection{A mimese como representação: a perspectiva de Paul Ricoeur}

A discussão filosófica sobre a tríplice mimese realizada por Paul Ricoeur (1994) em Tempo e Narrativa ajuda a entender a construção das representações, bem como o papel da experiência nesse processo. Isso porque é possível pensar a mimese como representação, e o entendimento de seu processo de constituição é imprescindível para apreender a experiência do mundo através da linguagem. 0 objetivo

A perspectiva de Durkheim sobre as representações impulsiona desdobramentos tanto na Sociologia como em outras ciências, como a Psicologia. Para uma boa síntese dos desdobramentos da perspectiva durkeimiana na primeira, ver Minayo (2004). Para uma discussão sobre a apropriação do conceito de representações na segunda, ver Jodelet (2001). 
de Ricoeur é constituir a mediação entre tempo e narrativa a partir dos três estágios da mimese. Para 0 autor, os três modos miméticos permitem "estabelecer o papel mediador da tessitura da intriga entre um estágio da experiência prática que a precede e um estágio que a sucede" (RICOEUR, 1994, p. 87). Os três estágios, que apresentam uma configuração narrativa, podem ser pensados como: 1) 0 mundo anterior ao texto (mimese I); 2) 0 mundo do texto (mimese II); e 3) o mundo do leitor (mimese III).

0 estágio inicial do percurso evidencia que a ação dos homens se realiza a partir de um mundo previamente constituído através da linguagem; ou seja, agimos em função de representações, valores, normas, enfim, de um universo cultural existente. São esses processos culturais "que articulam a experiência inteira" (RICOEUR, 1994, p. 92). Conforme Ricoeur, "a composição da intriga está enraizada numa pré-compreensão do mundo e da ação: de suas estruturas inteligíveis, de suas fontes simbólicas e de seu caráter temporal" (RICOEUR, 1994, p. 88). Esse é o estágio da mimese I: 0 momento da pré-configuração do mundo que condiciona a relação entre o mundo do produtor e 0 mundo do texto e permite entender 0 agir humano. É a partir dessa compreensão que emerge a tessitura da intriga, a qual aponta para o segundo momento da mimese.
A mimese II é a fase da configuração da intriga, em que a linguagem é utilizada para a conformação dos sentidos inscritos no texto. Este é uma construção particular, que não se configura como um espelho do mundo préfigurado, mas se constitui como uma instância mediadora entre este e o mundo do leitor. Ricoeur destaca dois traços característicos desse ato configurante: a esquematização e 0 tradicionalismo. A esquematização é realizada através da imaginação produtora: esta desempenha uma função sintética ao ordenar os elementos prefigurados. Essa produção sintética da imaginação acontece a partir da tradição:

Esse esquematismo [...] constitui-se numa história que tem todas as características de uma tradição. Entendemos por isso não a transmissão inerte de um depósito já morto, mas a transmissão viva de uma inovação sempre suscetível de ser reativada por um retorno aos momentos mais criadores de fazer poético. Assim compreendido, o tradicionalismo enriquece a relação da intriga com 0 tempo com um traço novo (RICOEUR, 1994, p. 107 , grifos do autor).

0 autor destaca, assim, o jogo entre inovação e sedimentação que caracteriza a tradição: existem elementos sedimentados que constroem um repertório pré-figurado, o qual é atualizado a partir das rupturas que as inovações podem acarretar no ato configurante. A tradição não é um lugar estável, ela comporta mudanças a partir da imaginação e das inovações abertas pela mimese II. 
A transição entre as mimeses II e a III é operada através do ato de leitura: isso "significa que é bem no ouvinte ou no leitor que se conclui o percurso da mimese" (RICOEUR, 1994, p. 110). Para Ricoeur, é a ação do leitor que é responsável pela refiguração do mundo do texto: este "só se torna obra na interação entre texto e receptor" (RICOEUR, 1994, p. 118). 0 movimento que efetiva o percurso mimético depende, assim, da experiência dos sujeitos responsáveis pela interpretação das representações configuradas por uma obra. A completude do processo "é não apenas que alguém tome a palavra e dirija-se a um interlocutor, é também que ambicione levar à linguagem e partilhar com outro uma nova experiência. É essa experiência que, por sua vez, tem o mundo como horizonte" (RICOEUR, 1994, p. 119-120, grifo do autor).

Ricoeur destaca, assim, a interação que efetiva a mimese, através de um compartilhamento de experiências, as quais se situam em um horizonte de potencialiades. Ele enfatiza o movimento dinâmico que caracteriza o processo de constituição das representações: uma em relação às outras, e estas em relação ao mundo. Partindo de um mundo pré-figurado, a representação se configura através da combinação de sentidos em um texto, que se oferece como um mundo a ser lido pelo leitor. Este, por sua vez, realiza seu ato de leitura, partindo também de um mundo pré-figurado, a partir do qual interpreta a forma simbólica em questão, completando um percurso e iniciando um novo: sua interpretação refigura o mundo não apenas do texto, mas de si mesmo $\mathrm{e}$ do contexto em que se inscreve.

Pode-se perceber, assim, o lugar central que a experiência ocupa na construção das representações na discussão de Ricoeur. Se existe um mundo pré-figurado que orienta a ação dos indivíduos, é porque a experiência humana o constituiu; o universo simbólico que marca a vida social não existe de modo independente dos sujeitos. A ação destes é fundamental na pré-figuração do mundo e em sua atualização. 0 movimento que inicia a instauração de uma representação é feito a partir da afetação que um dos elementos do mundo exerce sobre os indivíduos, os quais agem a partir desse padecimento. Nesse processo, sujeitos, mundo e representações se afetam e se modificam reciprocamente.

Se a linguagem é central nessa pré-figuração do mundo, ela também o é no ato configurante que resulta em um texto. É ela que torna possível a articulação dos sentidos que compõem a obra, revelando a interação entre o produtor e 0 texto na experiência que marca a mimese II. Experiência essa que só se completa a partir da ação do interlocutor: ele é responsável por interpretar as representações propostas e articular novos sentidos no contexto em que o processo ocorre. Acionando um repertório de experiências passadas, o leitor se apropria dos significados, os quais atualizam a sua vivência presente e passam a compor o quadro simbólico que pré-figurará outras experiências e representações no futuro. 
É nesse sentido que é possível afirmar que o fluxo de significações que configura os três estágios miméticos, ou seja, o processo de constituição de representações, é instituído a partir das interações que caracterizam a experiência humana e, ao mesmo tempo, é instituidor de novas experiências em um movimento dinâmico que marca 0 mundo intersubjetivo. Essa visão de que as representações são instituídas pela experiência e são instituidoras de novas experiências também está presente na discussão de Gilbert Durand, como veremos a seguir.

\subsection{Representação e simbólico:} na trilha de Gilbert Durand

A representação do mundo também é objeto de reflexão do filósofo e antropólogo Gilbert Durand. Já na introdução de $A$ imaginação simbólica, 0 autor propõe que a consciência humana apresenta duas formas de representar o mundo: "uma directa, na qual a própria coisa parece estar presente no espírito, como na percepção ou na simples sensação. A outra indirecta quando, por esta ou por aquela razão, a coisa não pode apresentar-se 'em carne e osso' à sensibilidade" (DURAND, 1993, p. 7). Nesse último caso, de consciência indireta, "o objecto ausente é representado na consciência por uma imagem, no sentido muito lato do termo" (DURAND, 1993, p. 7, grifos do autor).

A representação direta se refere, assim, à apreensão do mundo através dos sentidos, em uma dimensão sensível, sinestésica. 0 segundo tipo de representação é caracterizado por uma apreensão propriamente simbólica do mundo, em um processo mediado. Essa apreensão indireta do mundo acontece de diferentes maneiras, a partir de três categorias de signos diferentes: a) o signo arbitrário; b) a alegoria; c) o símbolo.

Em uma primeira acepção, o signo apresenta um sentido estrito e é definido, arbitrariamente, por uma convenção: ele remete "para uma realidade significada, se não presente pelo menos sempre apresentável" (DURAND, 1993, p. 9). A alegoria constitui-se quando é preciso remeter para abstrações, qualidades espirituais ou do domínio moral, configurando-se como uma "'tradução' concreta de uma ideia difícil de compreender ou de exprimir de maneira simples" (DURAND, 1993, p. 9). 0 símbolo, por sua vez, remete à imaginação simbólica e à capacidade humana de refletir. Essa capacidade possibilita a ampliação de horizontes, a realização de novas experiências. Afinal, o símbolo é uma "representação que faz aparecer um sentido secreto, é a epifania de um mistério" (DURAND, 1993, p. 12), promovendo a abertura e a mobilidade de sentidos.

A fim de sustentar a sua posição segundo a qual o símbolo é o signo capaz de remeter "para um indizível e invisível significado" (DURAND, 1993, p. 16), Durand constrói uma genealogia que busca evidenciar o modo como a representação foi tratada (e negligenciada) pela ciência e pelos indivíduos. A cultura ocidental, segundo o autor, procurou depreciar 
os símbolos e extinguir o simbólico da vivência dos indivíduos e da preocupação das ciências. Esse processo foi iniciado com a corrente científica do cartesianismo: este "assegura 0 triunfo do 'signo' sobre o símbolo. A imaginação, como aliás a sensação, é refutada por todos os cartesianos como a mestre do erro" (DURAND, 1993, p. 21). Essa regressão progressiva do campo do simbólico conduz "a uma concepção e a um papel excessivamente 'acanhado' do simbolismo" (DURAND, 1993, p. 35).

Alguns movimentos do século XX são retomados por Durand como centrais na retomada de consciência da importância das imagens simbólicas na vida mental: a psicanálise e a etnologia. Estas, entretanto, são caracterizadas pelo autor como hermenêuticas redutoras, na medida em que emerge uma concepção redutora do simbólico: este é valorizado sim, mas não em sua transcendência. Conforme Durand,

Para a psicanálise, 0 inconsciente é uma verdadeira faculdade sempre "plena", e simplesmente repleta do potencial energético da libido. 0 ambiente social, as situações da vida individual vêm modelar de múltiplas maneiras, vêm "metamorfosear" e velar mais ou menos esta corrente única de vida, este impulso específico cujo poder vital transvasa por todos os lados a clara vontade individual e deixa constantemente marcas no conteúdo da representação, dando cor a todas as imagens e atitudes (DURAND, 1993, p. 51-52).

Se 0 inconsciente pode ampliar 0 campo simbólico - a partir dos sonhos e desejos que 0 constituem -, ele é visto, por Freud, como aquilo que nos constrange, que é reprimido e modelado pela situação social. Na etnologia, por sua vez, "0 inconsciente 'está sempre vazio', 'tão estranho às imagens como 0 estômago aos alimentos que 0 atravessam', limita-se a 'impor as leis estruturais' e a estruturação [...] integra nas suas formas simples as imagens, os semantemas veiculados pelo social" (DURAND, 1993, p. 52).

Nessa hermenêutica redutora caracterizada por Durand, as imagens que povoam o universo simbólico - como os mitos estudados pelos antropólogos - são vistas como projeções da vida social e não apreendidos em sua potencialidade constitutiva. Para além das diferenças entre esses dois movimentos, 0 autor destaca que, em ambos, "a transcendência do simbolizado é sempre negada a favor de uma redução ao simbolizante explicitado" (DURAND, 1993, p. 52). Elas negariam, assim, a potencialidade de abertura dos sentidos que é a marca do simbólico.

Continuando a sua genealogia, Durand destaca as hermenêuticas instauradoras: abordagens que destacam as imagens como objeto de análise e percebem a potencialidade dos símbolos. 0 autor situa aqui a obra de Cassirer, Jung e Bachelard.

De Cassirer, Durand retoma a noção de carga simbólica, que se refere à impotência constitutiva do pensamento humano de não poder intuir objetivamente uma coisa. "Mas esta impotência constitutiva é apenas o inverso de um imenso poder: 0 da presença inelutável do sentido" (DURAND, 1993, p. 54-55, grifo do 
autor). 0 autor destaca, assim, a capacidade dos indivíduos de ler o mundo a partir da presença do simbólico e de constituir sua experiência a partir das representações. Na visão de Durand, entretanto, Cassirer constrói uma questionável hierarquia nas formas de cultura e do simbolismo, separando, por exemplo, o mito e a ciência.

As reflexões de Jung, bem como as críticas por ele realizadas à psicanálise freudiana, são destacadas por Durand como fundamentais no resgate da potencialidade do simbólico na experiência humana. 0 autor ressalta que a teoria de Jung sobre o papel das imagens é muito profunda, na medida em que situa, ao lado do signo-sintoma evidenciado por Freud (e que remete ao ato falho, que deve ser reprimido), o símboloarquétipo. Este se refere a um "centro de força invisível", a "uma forma dinâmica, uma estrutura organizadora das imagens, mas que transvaza sempre as concreções individuais, biográficas, regionais e sociais, da formação das imagens" (DURAND, 1993, p. 56).

Jung destaca, assim, a potencialidade de abertura dos significados, do "mundo da irrupção simbólica", que marca a psique humana. Ao mesmo tempo, ele enfatiza a dimensão coletiva desse processo de individuação, na medida em que são os usos e costumes que ajudam a preencher essas formas dinâmicas que são os arquétipos nas diferentes civilizações. Apesar dessas contribuições, Durand ressalta que 0 sistema de Jung parece ainda confundir "a consciência simbólica criadora da arte e da religião e a consciência simbólica criadora das simples alucinações do delírio, do sonho e da aberração mental" (DURAND, 1993, p. 60).

Bachelard propõe pensar a utilização dos símbolos a partir de três setores: a) o da ciência; b) o dos sonhos; c) o da palavra humana.

Para 0 autor, este terceiro setor é específico da humanidade que existe em nós e diz respeito ao símbolo, à linguagem que brota do gênio da espécie (DURAND, 1993, p. 61). Na visão de Durand, persiste em Bachelard um dualismo que distingue 0 "consciente racional dos outros fenómenos psíquicos e, em particular, das franjas subconscientes do imaginário" (DURAND, 1993, p. 75). Para Durand, deve-se pensar o imaginário em sua totalidade, sem dualismos ou hierarquias.

Ao construir essa genealogia, Durand chama a atenção para a necessidade de colocar a imaginação e 0 imaginário no foco das ciências, evidenciando o seu potencial transcendente de ampliar o campo simbólico para os indizíveis e invisíveis significados. A partir das contribuições e das críticas em relação às hermenêuticas discutidas, Durand propõe uma teoria do imaginário que evidencia a capacidade humana de criar mundos, de construir sistemas de representação. Ele destaca, ainda, o papel da imaginação simbólica na configuração de um equilíbrio mental e psicossocial; ela é essencial na constituição do mundo intersubjetivo. Afinal, 
"o que liga os homens entre si, ao humilde nível das felicidades e das penas quotidianas da espécie humana, é a representação afectiva, porque vivida, que o império das imagens constitui" (DURAND, 1993, p. 104). É o terreno das representações, do simbólico em sua potencialidade, que funda as relações entre os sujeitos e a própria vida social com a totalidade da cultura humana.

Essa discussão que Gilbert Durand realiza sobre a imaginação simbólica também permite enfatizar a articulação entre experiência e representação. Se a experiência é entendida como resultado da interação entre os homens e o mundo, é possível dizer que ela se efetiva a partir das formas de representá-lo. É interagindo com os outros e com o mundo que o indivíduo o apreende tanto perceptivamente, através de um processo sensorial direto, como a partir da apreensão propriamente simbólica (e a criação de signos, alegorias e, principalmente, símbolos). É a experiência humana que funda as representações (tanto as que têm sentidos mais estritos como as capazes de alargar a experiência a partir de significados invisíveis).

Ao apreender o mundo, criando diferentes tipos de representação, 0 indivíduo age em relação às coisas e pode revelar a epifania de um mistério. Ao mesmo tempo, ele sofre os efeitos da abertura de significados que o mistério desencadeia, transformando o mundo, 0 outro e a si mesmo. Como salientamos, esse processo de ação, padecimento e transformação que marca a experiência é realizado através da linguagem. Durand também destaca o papel desta como mediadora essencial na edificação dos símbolos que constituem a experiência.

Ao construir sua genealogia, Durand enfatiza as dimensões individual e social de efetivação da experiência humana através das representações. Ao retomar a ideia de carga simbólica, 0 autor destaca o papel dos indivíduos na configuração dos sentidos; essa faculdade de imaginar é a marca do ser do homem em sociedade. Sem negligenciar a dimensão individual, o filósofo ressalta a dimensão social da experiência: são os usos, costumes e valores que marcam a sociedade, que atuam no preenchimento dos símbolos arquetípicos que são atualizados em diferentes culturas. É nesse movimento entre o indivíduo (que imagina, constrói sentidos e apreende o mundo) e o social (que dinamiza, atualiza e reorienta os significados) que 0 universo de representações se edifica através da experiência. Assim, a experiência é fundadora das representações, frutos, portanto, de nosso embate com o mundo; ao mesmo tempo, elas reorientam nossa vivência, permitindo que, através das apreensões que realizamos da realidade, a nossa própria prática se constitua.

\section{Apontamentos Finais}

0 objetivo deste trabalho foi apreender a centralidade da experiência na constituição das representações, procurando construir 
uma abordagem que enriqueça os estudos no campo da comunicação. Para tanto, partimos de uma concepção pragmatista de experiência, que a entende como prática, como contexto, como resultado das interações que os indivíduos estabelecem entre eles e com o mundo, enfatizando a ação, o padecimento e a transformação dos elementos envolvidos que a caracterizam. Procuramos evidenciar 0 papel central que a linguagem desempenha na instauração da experiência, articulando sentidos e temporalidades na conformação das vivências. É a experiência, portanto, que, através da linguagem, constitui o fluxo de significações, ou seja, as representações. Estas são entendidas como universos simbólicos que emergem em contextos interacionais. São constituídas pelos sujeitos em suas práticas cotidianas, orientando formas de vida; ao mesmo tempo, as representações existentes reorientam a experiência humana, em um processo reflexivo.

Para refletir sobre essa articulação entre experiência e representação, retomamos algumas ideias de Durkheim, Ricoeur e Durand acerca das representações. A tradição durkheimiana atenta para as representações coletivas, as quais apresentam uma existência relativamente autônoma e independente em relação aos indivíduos. Esse agregado simbólico superior é apreendido em sua exterioridade, mas não se destacam os processos que 0 instituem através da linguagem. Ainda que a experiência individual seja tematizada como importante nos processos de construção dos significados, o movimento interativo que configura as experiências e instaura as representações é negligenciado em sua dinamicidade por Durkheim.

Em Ricoeur, por sua vez, é possível resgatar a complexidade da constituição das representações, bem como o papel da experiência nesse processo. Ele destaca que a configuração de um universo simbólico tem como ponto de partida o mundo pré-figurado pela experiência social. A representação construída por um texto só se completa no momento em que ela é refigurada por um interlocutor. Este atualiza o texto e sua própria experiência na apropriação simbólica que realiza. Dessa forma, todo o processo mimético, ou seja, de constituição de representações, acontece a partir das experiências dos sujeitos no mundo através da linguagem. Ao mesmo tempo, além de o fluxo de representações ser instituído pela experiência humana, ele é instituidor de novas experiências. Essa abordagem enfatiza, assim, a dimensão interativa que configura as representações e a própria experiência que as constitui. Os significados produzidos e interpretados pelos indivíduos não existem como dados existentes a priori na sociedade; eles só ganham existência pela ação dos sujeitos que também são responsáveis por sua atualização nos diferentes contextos.

0 movimento que articula experiência e representação também é evidente na reflexão de Durand, que tem como ponto de partida 0 
indivíduo e a capacidade humana de representar 0 mundo. 0 pensador enfatiza o potencial do simbólico na ampliação de horizontes, na criação de mundos e na abertura de significados que podem marcar as relações sociais. É ao longo dessas interações que os sujeitos apreendem o mundo e constroem suas experiências. A experiência se constitui, assim, a partir dessa produção simbólica que os indivíduos constroem através da linguagem. Mas essa dimensão individual não é suficiente no processo: Durand destaca o papel do social na atualização dos significados. Afinal, é no movimento entre indivíduos e sociedade que o universo de representações se constitui através da experiência.

Acreditamos que essa compreensão de que a experiência é fundadora das representações, ao mesmo tempo em que estas reconfiguram experiências, é fundamental para as análises no campo da comunicação. Compartilhamos da visão segundo a qual

A comunicação é esse processo em que imagens, representações são produzidas, trocadas, atualizadas no bojo de relações; esse processo em que sujeitos interlocutores produzem, se apropriam e atualizam permanentemente os sentidos que moldam seu mundo e, em última instância, o próprio mundo. Portanto, o lugar da comunicação (das práticas comunicativas) é um lugar constituinte - e 0 olhar (abordagem) comunicacional é um olhar que busca apreender esse movimento de constituição (FRANÇA, 2004, p. 23).

Dessa forma, 0 viés comunicacional deve atentar para esse movimento de produção e atualização do simbólico a partir da ação dos sujeitos no mundo; deve procurar apreender como as experiências fundam as representações, as quais, por sua vez, reorientam as ações dos indivíduos que atualizam experiências; deve, enfim, buscar dar conta da dinamicidade e da complexidade do processo que constitui as representações a partir das experiências individuais e coletivas que constroem a vida social.

\section{Referências}

DEWEY, John. Tendo uma experiência. In:

Os Pensadores. São Paulo: Abril Cultural, 1980. p. 89-105. DURAND, Gilbert A imaginação simbólica. Lisboa: Edições 70, 1993.

DURKHEIM, Émile. Representações individuais e coletivas. In: . Sociologia e Filosofia. 2. ed. São Paulo: Ícone, 2007. p. 9-43.

FOUCAULT, Michel. As palavras e as coisas: uma arqueologia das ciências humanas. Lisboa: Portugália, 1966.

FRANÇA, Vera Regina Veiga. Representações, mediações e práticas comunicativas. In: PEREIRA, Miguel; GOMES, Renato Cordeiro; FIGUEIRED0, Vera Lúcia Follain de. Comunicação, representação e práticas sociais. v. 1. Rio de Janeiro: PUC Rio; Aparecida: Idéias \& Letras, 2004. p. 13-26.

GUIMARÃES, César Geraldo; LEAL, Bruno Souza. Experiência estética e experiência mediada. Intexto, Porto Alegre, v. 2, n. 9, p. 1-14, 2008.

JODELET, Denise. (org.). As representações sociais. Rio de Janeiro: UERJ, 2001.

\section{MINAYO, Maria Cecília de Souza. 0 desafio do} conhecimento: pesquisa qualitativa em saúde. 8. ed. São Paulo: Hucitec, 2004. 
PINHEIRO FILHO, Fernando. A noção de

representação em Durkheim. Lua Nova, São Paulo, n. 61, p. 139-155, 2004.

POGREBINSCHI, Thamy. Pragmatismo: teoria social e política. Rio de Janeiro: Relume Dumará, 2005.

RICOEUR, Paul. Tempo e Narrativa. Tomo 1.

Campinas: Papirus, 1994.

RODRIGUES, Adriano Duarte. Arte e experiência.

Revista de Comunicação e Linguagem, Lisboa, $n$. 12/13, p. 25-33, 1991.

VALVERDE, Monclar. Estética da Comunicação:

sentido, forma e valor nas cenas da cultura. Salvador:

Quarteto, 2007. 
The central role of experience in the construction of representations: interdisciplinary contributions to communication studies

\section{Abstract}

This paper aims to discuss the role of experience in the constitution of representations. It starts by defining the notion of experience, by analyzing John Dewey's pragmatist approach and some contemporary contributions. It then discusses the concept of representation, exploring Durkheim's canonical definition, Paul Ricoeur's idea of mimesis and Gilbert Durand's notion of symbolic imagination. The paper highlights the complexity and dynamicity that marks the flows of signification. It emphasizes the role played by the symbolic in the construction of individuals and society, as well as the interactive dimension of experience. Moreover, the article stresses how experience and representation constitute each other; something essential to analyses in the field of communication studies.

\section{Keywords}

Representation. Experience.

Communication. Interaction.

\section{La centralidad de la experiencia} en la formación de las representaciones: contribuiciones interdisciplinares para el campo de la comunicación

\section{Resumen}

El objetivo de este texto es discutir el papel de la experiencia en la formación de las representaciones. Desde la definición de experiencia, se busca analizar el enfoque pragmático de John Dewey y algunas otras contribuciones contemporáneas. Para esto, se discute el concepto de representación a partir de tres concepciones: la concepción clásica de Durkheim sobre el término, la idea de la mimesis de Paul Ricoeur y la noción de imaginación simbólica de Gilbert Durand. El artículo pone de relieve la complejidad y el dinamismo que marcan los flujos de sentido. Además de esto, enfatiza el papel de la construcción simbólica de los sujetos y de la sociedad, así como apunta para la dimensión de la experiencia interactiva. También destaca la construcción mutua entre la experiencia y la representación, algo fundamental para el análisis en el ámbito de la comunicación.

\section{Palabras clave}

Representación. Experiencia.

Comunicación. Interacción. 


\section{Expediente}

A revista E-Compós é a publicação científica em formato eletrônico da Associação Nacional dos Programas de Pós-Graduação em Comunicação (Compós). Lançada em 2004, tem como principal finalidade difundir a produção acadêmica de pesquisadores da área de Comunicação, inseridos em instituições do Brasil e do exterior.
E-COMPÓS I www.e-compos.org.br I E-ISSN 1808-2599

Revista da Associação Nacional dos Programas de Pós-Graduação em Comunicação. Brasília, v.13, n.1, jan./abr. 2010.

A identificação das edições, a partir de 2008 passa a ser volume anual com três números.

\section{CONSELHO EDITORIAL}

Afonso Albuquerque

Universidade Federal Fluminense, Brasil

Alberto Carlos Augusto Klein

Universidade Estadual de Londrina, Brasil

Alex Fernando Teixeira Primo

Universidade Federal do Rio Grande do Sul, Brasil

Alfredo Vizeu

Universidade Federal de Pernambuco, Brasil

Ana Carolina Damboriarena Escosteguy

Pontifícia Universidade Católica do Rio Grande do Sul, Brasil

Ana Silvia Lopes Davi Médola

Universidade Estadual Paulista, Brasil

André Luiz Martins Lemos

Universidade Federal da Bahia, Brasil

Ângela Freire Prysthon

Universidade Federal de Pernambuco, Brasil

Antônio Fausto Neto

Universidade do Vale do Rio dos Sinos, Brasil

Antonio Carlos Hohlfeldt

Pontifícia Universidade Católica do Rio Grande do Sul, Brasil

Arlindo Ribeiro Machado

Universidade de São Paulo, Brasil

César Geraldo Guimarães

Universidade Federal de Minas Gerais, Brasil

Cristiane Freitas Gutfreind

Pontifícia Universidade Católica do Rio Grande do Sul, Brasil

Denilson Lopes

Universidade Federal do Rio de Janeiro, Brasil

Eduardo Peñuela Cañizal

Universidade Paulista, Brasil

Erick Felinto de Oliveira

Universidade do Estado do Rio de Janeiro, Brasil

Francisco Menezes Martins

Universidade Tuiuti do Paraná, Brasil

Gelson Santana

Universidade Anhembi/Morumbi, Brasil

Goiamérico Felício

Universidade Federal de Goiás, Brasil

Hector Ospina

Universidad de Manizales, Colômbia

Herom Vargas

Universidade Municipal de São Caetano do Sul, Brasil

leda Tucherman

Universidade Federal do Rio de Janeiro, Brasil

Itania Maria Mota Gomes

Universidade Federal da Bahia, Brasil

Janice Caiafa

Universidade Federal do Rio de Janeiro, Brasil

Jeder Silveira Janotti Junior

Universidade Federal da Bahia, Brasil
João Freire Filho

Universidade Federal do Rio de Janeiro, Brasil

John DH Downing

University of Texas at Austin, Estados Unidos

José Luiz Aidar Prado

Pontifícia Universidade Católica de São Paulo, Brasil

José Luiz Warren Jardim Gomes Braga

Universidade do Vale do Rio dos Sinos, Brasil

Juremir Machado da Silva

Pontifícia Universidade Católica do Rio Grande do Sul, Brasil

Lorraine Leu

University of Bristol, Grã-Bretanha

Luiz Claudio Martino

Universidade de Brasília, Brasil

Maria Immacolata Vassallo de Lopes

Universidade de São Paulo, Brasil

Maria Lucia Santaella

Pontifícia Universidade Católica de São Paulo, Brasil

Mauro Pereira Porto

Tulane University, Estados Unidos

Muniz Sodre de Araujo Cabra

Universidade Federal do Rio de Janeiro, Brasil

Nilda Aparecida Jacks

Universidade Federal do Rio Grande do Sul, Brasil

Paulo Roberto Gibaldi Vaz

Universidade Federal do Rio de Janeiro, Brasil

Renato Cordeiro Gomes

Pontifícia Universidade Católica do Rio de Janeiro, Brasil

Ronaldo George Helal

Universidade do Estado do Rio de Janeiro, Brasil

Rosana de Lima Soares

Universidade de São Paulo, Brasil

Rossana Reguillo

Instituto Tecnológico y de Estudios Superiores do Occidente, México

Rousiley Celi Moreira Maia

Universidade Federal de Minas Gerais, Brasil

Samuel Paiva

Universidade Federal de São Carlos, Brasil

Sebastião Albano

Universidade Federal do Rio Grande do Norte, Brasil

Sebastião Carlos de Morais Squirra

Universidade Metodista de São Paulo, Brasil

Simone Maria Andrade Pereira de Sá

Universidade Federal Fluminense, Brasil

Suzete Venturelli

Universidade de Brasília, Brasil

Valério Cruz Brittos

Universidade do Vale do Rio dos Sinos, Brasil

Veneza Mayora Ronsini

Universidade Federal de Santa Maria, Brasil

Vera Regina Veiga França

Universidade Federal de Minas Gerais, Brasil

\section{COMISSÃO EDITORIAL}

Felipe da Costa Trotta I Universidade Federal de Pernambuco, Brasil Rose Melo Rocha I Escola Superior de Propaganda e Marketing, Brasil CONSULTORES AD HOC

João Maia I Universidade do Estado do Rio de Janeiro, Brasil Sandra Gonçalves I Universidade Federal do Rio Grande do Sul, Brasil Mayra Rodrigues Gomes I Universidade de São Paulo, Brasil Gisela Castro I Escola Superior de Propaganda e Marketing, Brasil João Carrascoza I Escola Superior de Propaganda e Marketing, Brasil Luciana Pellin Mielniczuk I Universidade Federal de Santa Maria, Brasil Irene de Araújo Machado I Universidade de São Paulo, Brasil Hermilio Pereira dos Santos Filho I Pontifícia Universidade Católica, Brasil Benjamim Picado I Universidade Federal Fluminense, Brasil Maria Apaecida Baccega I Escola Superior de Propaganda e Marketing, Brasil Rogério Ferraraz I Universidade Anhembi Morumbi, Brasil

Bruno Souza Leal I Universidade Federal de Minas Gerais, Brasi REVISÃO DE TEXTO E TRADUÇÃo I Everton Cardoso EDITORAÇ̃̃ ELETRÔNICA I Roka Estúdio
COMPóS I www.compos.org.br

Associação Nacional dos Programas de Pós-Graduação em Comunicação

Presidente

Itania Maria Mota Gomes

Universidade Federal da Bahia, Brasil

itania@ufba.br

Vice-presidente

Julio Pinto

Pontifícia Universidade Católica de Minas Gerais, Brasil juliopinto@pucminas.br

Secretária-Geral

Ana Carolina Escosteguy

Pontifícia Universidade Católica do Rio Grande do Sul, Brasil carolad@pucrs.br 